\title{
Factors Influencing Childhood Immunization Defaulters in Sabah, Malaysia
}

\author{
Shamsul Azhar S, ${ }^{a}$ Nirmal K, ${ }^{\mathrm{b}}$ Nazarudin S, ${ }^{\mathrm{a}}$ Rohaizat H, ${ }^{\mathrm{a}}$ Azimatun Noor A, ${ }^{a}$ Rozita $\mathrm{H}^{\mathrm{a}}$ \\ ${ }^{a}$ Department of Community Health, UKM Medical Centre, Cheras, Kuala Lumpur \\ ${ }^{b}$ Sabah State Health Department
}

ABSTRACT

Introduction: The purpose of this study was to determine the prevalence of defaulters of immunization, and their associated risk factors among children age 12 to 24 months. Materials and Methods: A cross-sectional study was conducted in all government's maternal child health clinics in District of Kota Kinabalu, Sabah. Data was collected using a standardised questionnaire from July to November 2006. Results: The prevalence rate for defaulting immunization was $16.8 \%$ from the 315 respondents. Bivariable analysis showed various significant factors associated with defaulters such as mother's employment status, family mobility, transportation and cost. Nonetheless, multivariable analysis showed only mother's age, mother employment status and family size were the significant predictors for defaulting immunization. Immunization that had the highest rate of defaulters was DPT-OPV booster dose (56.6\%), followed by MMR immunization (43.4\%) and DPT-Hib/OPV and Hep B third dose (37.7\%).Conclusion: Employed mothers with bigger family size should be more closely monitored and advised to reduce the chance of defaulting on the immunization. Health promotion activities also should focus to these groups of mothers.

KEYWORDS: Immunization, defaulters, children, risk factors.

\section{INTRODUCTION}

Immunization is the main health intervention to reduce child mortality. One-quarter of the 2002 under five-mortality rate is attributable to vaccinepreventable diseases. ${ }^{1}$ Low rates of immunization not only leave many young children at risk for various serious vaccine-preventable diseases but also serve as an indicator of an inadequate recipient of other preventive health care. ${ }^{2}$

As part of the overall package of maternal and child health services in Malaysia, all children are provided with free immunization. It is available in all government health facilities where child health services are provided, both in rural and urban areas. Private sector, through private clinics and hospitals supplement the services.

Because of the importance of the immunization, it is crucial that the implementation of the programme be monitored very closely. One of the challenges of this programme is a failure of receiving the

\footnotetext{
Corresponding author:

Nazarudin Safian

Department of Community Health,

Universiti Kebangsaan Malaysia Medical Centre,

Jalan Yaacob Latif, Bandar Tun Razak,

Cheras, 56000 Kuala Lumpur, Malaysia.

E-mail: zanadurin@gmail.com

Telephone: +603-91455887,

Fax: $+603-91456670$.
}

recommended vaccination at the recommended time or in easier term, defaulting immunization.

Factors influencing compliance to the recommended immunization could be divided into client factors, provider factors and external or environmental factors. ${ }^{3,4}$ Client factors include lack of knowledge or inaccurate perception about the importance of vaccines and the seriousness of the diseases prevented by the vaccines, socioeconomic status, high birth order and big family size, single parent and families who live in temporary housing or who migrate between jobs. ${ }^{5}$

The provider factors include waiting time, motivation of service providers, suitability of the timing of immunization sessions, attitude of service providers, reaction to side effects and charges for the services. The external or environmental factors included logistic barriers, limited accessibility to health care due to poor roads or inadequate public transportation, preparedness of community for immunization sessions, information dissemination among the community and inter-sectoral collaboration.

However, minimal research has been carried out to determine the factors influencing defaulters of childhood immunization in Malaysia, including in Sabah where the majority of the area still lacks basic infrastructure, especially in the rural areas. Hence, this study was conducted to determine the prevalence of defaulters of immunization and their associated factors among children from the age of 12 to 24 months. 


\section{MATERIALS AND METHODS}

A cross-sectional study was carried out over a period of five months (July to November 2006) in all the 10 maternal and child health $(\mathrm{MCH})$ clinics in Kota Kinabalu district. The study population was all children age from 12 to 24 months who attended the $\mathrm{MCH}$ clinics in Kota Kinabalu district for their immunization. The age group of $12-24$ months was selected because most of the recommended immunizations were for the children age less than 12 months.

All children age 12 to 24 months attending the maternal and child health clinics in Kota Kinabalu district were taken as the subjects. We reviewed the immunization status of the children using their immunization record from birth to their stated age. Children who had defaulted on one or more doses of vaccination from birth to their respective age were taken as defaulters of immunization, while those children whose immunization status was up to date for their age were taken as non-defaulters. The sampling was conducted using purposive sampling method.

We collected the data through an interview with the mothers (respondents) of the children who attended maternal and child health clinics for their immunization using a set of a standardized questionnaire. The questionnaire consisted of four parts that covered child, maternal, family and health service related factors.

\section{RESULTS}

A total of 315 subjects responded to the survey. Table 1 shows the characteristics of the respondents. The mean age of the mothers who responded was $27 \pm 6.2$ years. Only five of them were single mothers due to divorce or living separately. A couple that lived together (cohabitant) were classified as married. Most of the mothers $(65.4 \%)$ attained secondary education level and $7.3 \%$ had no formal education.

For the children's characteristics, from 315 children, the age ranged from 12 to 24 months with mean age of $17 \pm 3.9$ months. Fifty-one per cent of them were males. Majority of them were delivered in the hospital with only seven delivered at home. Fifty-three respondents (16.8\%) fulfilled the classification of defaulters, i.e. those children who did not receive their recommended immunization on the exact date as scheduled for their age for at least one dose.

Table 1: Characteristic of the respondents

Number 310

Single

Education Level

No formal education

Primary

Secondary

Employment Status

Unemployed

Employed

Children Characteristic

Female

Male

Outcome

Defaulter

Non defaulter 
Table 2: Defaulters of Immunization according to Type of Vaccine

Type of Vaccine
Recommended age given

(months)
Percentage of defaulting

$\begin{array}{lll}\text { Hepatitis B }-2^{\text {nd }} \text { dose } & 2 & 5.7 \\ \text { Hepatitis B }-3^{\text {rd }} \text { dose } & 5 & 37.7 \\ \text { DPT-Hib-OPV }-1^{\text {st }} \text { dose } & 2 & 9.4 \\ \text { DPT-Hib-OPV }-2^{\text {nd }} \text { dose } & 3 & 20.8 \\ \text { DPT-Hib-OPV }-3^{\text {rd }} \text { dose } & 5 & 37.7 \\ \text { Measles (Sabah only) } & 6 & 24.5 \\ \text { MMR } & 12 & 43.4 \\ \text { DPT- OPV booster dose } & 18 & 56.6\end{array}$

Table 2 shows the percentage of different types of immunization defaulted by the children. The highest number of defaulters was for the booster dose of DPT-OPV immunization $(56.6 \%)$ followed by MMR immunization $(43.4 \%)$. The rate of defaulters for measles immunization was $24.5 \%$.

The recommended age for measles vaccination in Sabah at six months is different from Peninsular Malaysia because of the higher incidence of measles in Sabah. ${ }^{6}$ Among the doses of Hepatitis immunization, the third dose has the most defaulters $(37.7 \%)$ followed by the second dose $(5.7 \%)$ while there were no defaulters for the first dose. The rate of defaulters for DPT-Hib1 + OPV1 was $9.4 \%$, followed by the second dose $(20.8 \%)$ and the $3^{\text {rd }}$ dose $(37.7 \%)$. These results showed that repeated dose of a vaccination increased the rate of defaulting subsequent dosages.

\section{Characteristic of Defaulters}

\section{- Child Characteristics}

There were more male children in the defaulter group compared with the non-defaulter group, but the difference was not statistically significant. There were six home deliveries in the non-defaulter group compared to only one in the defaulter group, but the different was not significant. There was no significant difference in terms of the health status of the children during the immunization period ( $p=0.056)$. All the children in the nondefaulter group were healthy, whereas, two children in the defaulter group were unhealthy with fever or diarrhoea symptoms while attending the immunization session.

\section{- Maternal Characteristics}

There was no significant difference in terms of age $(t=1.07, p=0.285$ ) between mothers of the non-defaulter (mean age was $28 \pm 6.1$ ), and mothers in defaulter group $(29 \pm 6.7)$. All the mothers in Volume 11 Number 1 June 2012 defaulter group were married but for the nondefaulter group, five of the mothers were single parents. For both groups, most of the mothers attained secondary-level education followed by primary and no formal education. The proportion of mothers with no formal education was higher in the non-defaulter group (82.6\%). Mother's employment status showed a significant difference between the two groups in which $27.0 \%$ of employed mothers defaulted compare with $13.7 \%$ of unemployed mothers defaulted. $\left(x^{2}=7.193 ; p=0.007\right)$.

\section{- Socioeconomic Characteristics}

Table 3 shows that family mobility, transportation and cost were found to be significant factors, whereas family size and types of family were not. Waiting time and bad service experienced were found not to be the reasons for defaulting immunization as none of the respondents reported to experience it.

\section{Multivariable Analysis}

Binary logistic regression was performed to assess the association between the risk factors and defaulting immunization. Table 4 shows the results of the analysis. There were significant associations between defaulters of immunization with mother's employment status (OR 16.6, 95\% Cl: 5.6 - 49.3), family size (OR 4.1, 95\% Cl: $1.2-.14 .6$ ) and mother's age (OR $7.4,95 \% \mathrm{Cl}: 1.1-48.2$ ). Other factors did not show any significant findings.

\section{DISCUSSION}

The rate of defaulters of immunization for children age 12 - 24 months is this study was $16.8 \%$. This figure was lower compared to other studies who found $27.6 \%$ and $37.0 \%$ of defaulters in their respective studies, both done in Nigeria. ${ }^{7,8}$ 
Table 3: Child, Maternal and Socioeconomic Characteristics of Defaulters and Non-Defaulters of Immunization

\begin{tabular}{|c|c|c|c|c|}
\hline Factors & $\begin{array}{l}\text { Defaulter } \\
(n=53)\end{array}$ & Non-Defaulter $(n=262)$ & Statistic & $\mathrm{p}$ value \\
\hline $\begin{array}{c}\text { Maternal Age (years) } \\
(\text { mean } \pm \mathrm{sd})\end{array}$ & $29 \pm 6.7$ & $28 \pm 6.1$ & $t=1.070$ & 0.285 \\
\hline $\begin{array}{l}\text { Education level }[\mathrm{n}(\%)] \\
\text { No Formal Education } \\
\text { Primary } \\
\text { Secondary }\end{array}$ & $\begin{array}{l}4(17.4) \\
17(19.5) \\
32(15.6)\end{array}$ & $\begin{array}{l}19(82.6) \\
70(80.5) \\
173(84.4)\end{array}$ & $x^{2}=0.680$ & 0.712 \\
\hline $\begin{array}{l}\text { Marital status } \\
\text { Married } \\
\text { Single }\end{array}$ & $\begin{array}{l}53(17.1) \\
0\end{array}$ & $\begin{array}{l}257(82.9) \\
5(100)\end{array}$ & & $0.791^{-}$ \\
\hline $\begin{array}{l}\text { Employment } \\
\text { Unemployed } \\
\text { Employed }\end{array}$ & $\begin{array}{l}33(13.7) \\
20(27.0)\end{array}$ & $\begin{array}{l}208(86.3) \\
54(73.0)\end{array}$ & $x^{2}=7.193$ & $0.007^{*}$ \\
\hline $\begin{array}{c}\text { Child gender } \\
\text { Male } \\
\text { Female }\end{array}$ & $\begin{array}{l}30(19.5) \\
23(14.3)\end{array}$ & $\begin{array}{l}124(80.5) \\
138(85.7)\end{array}$ & $x^{2}=1.518$ & 0.218 \\
\hline $\begin{array}{l}\text { Health status of child } \\
\text { Healthy } \\
\text { Unhealthy }\end{array}$ & $\begin{array}{l}51(16.3) \\
2(100.0)\end{array}$ & $\begin{array}{l}262(83.7) \\
0(0.0)\end{array}$ & & $0.056^{\wedge}$ \\
\hline $\begin{array}{c}\text { Place of delivery } \\
\text { Hospital } \\
\text { Home }\end{array}$ & $\begin{array}{l}52(16.9) \\
1(14.3)\end{array}$ & $\begin{array}{l}256(83.1) \\
6(85.7)\end{array}$ & & $>0.999$ \\
\hline $\begin{array}{l}\text { Family Mobility } \\
\text { Yes } \\
\text { No }\end{array}$ & $\begin{array}{l}17(100.0) \\
36(12.1)\end{array}$ & $\begin{array}{l}0(0.0) \\
262(87.9)\end{array}$ & & $<0.0001^{*}$ \\
\hline $\begin{array}{l}\text { Family Type } \\
\text { Nucleus } \\
\text { Extended }\end{array}$ & $\begin{array}{l}34(16.7) \\
19(17.1)\end{array}$ & $\begin{array}{l}170(83.3) \\
92(82.9)\end{array}$ & $x^{2}=0.0104$ & 0.919 \\
\hline $\begin{array}{l}\text { Family Size (members) } \\
\quad>5 \\
\leq 5\end{array}$ & $\begin{array}{l}46(16.5) \\
7(19.4)\end{array}$ & $\begin{array}{l}233(83.5) \\
29(80.6)\end{array}$ & $x^{2}=0.1992$ & 0.3277 \\
\hline $\begin{array}{l}\text { Transportation } \\
\text { Available } \\
\text { Unavailable }\end{array}$ & $\begin{array}{l}5(100.0) \\
48(15.5)\end{array}$ & $\begin{array}{l}0(0.0) \\
262(85.5)\end{array}$ & & $0.0002^{*}$ \\
\hline $\begin{array}{c}\text { Cost problem } \\
\text { Yes } \\
\text { No }\end{array}$ & $\begin{array}{l}5(100.0) \\
48(15.5)\end{array}$ & $\begin{array}{l}0(0.0) \\
262(85.5)\end{array}$ & & $0.0002^{*}$ \\
\hline
\end{tabular}

${ }^{*} \mathrm{p}<0.05$ was taken as significant, $`$ Fisher exact test ( 2 tails)

Table 4: Factors associated with defaulters of immunization - multivariable analysis

\begin{tabular}{lllllll}
\hline Variables & Beta & SE & Wald stats & p value* & Odds Ratio* & 95\% Cl \\
& & & & & & \\
\hline Constant & -4.088 & 0.518 & 62.185 & 0.000 & 0.017 & \\
Employed Mothers & 2.807 & 0.557 & 25.425 & 0.000 & 16.564 & $5.563-49.325$ \\
Family Size & 1.412 & 0.648 & 4.753 & 0.029 & 4.105 & $1.153-14.612$ \\
Maternal Age & 2.003 & 0.956 & 4.396 & 0.036 & 7.413 & $1.139-48.234$ \\
Cost & 25.102 & 0.000 & 0.999 & & \\
Transportation & 25.291 & 0.000 & 0.999 & & \\
Family Mobility & 25.073 & 0.000 & 0.998 & & \\
Unhealthy Child & 25.291 & 0.000 & 0.999 & & \\
& & & & & & \\
\end{tabular}

*Binary logistic regression test - enter method, SE: standard error, $\mathrm{Cl}$ : confidence interval 
This study found that DPT-Hib booster dose $(56.6 \%)$ was the most frequent immunization defaulted. The commonest reason given by the mothers was that they assumed immunization completes once the child reaches one-year-old. They were not aware of the booster dose of DPT-OPV at one and a half years old, which is six months away as compared to the other immunization schedule.

MMR was the second immunization most defaulted in this study (43.4\%). Parents assumed that MMR immunization was an alternative for measles immunization that was given at six months of age and therefore, thought that it was not compulsory for their children to get the MMR immunization. DPT-Hib, OPV and Hep B third dose had the highest defaulters $(37.7 \%)$ when compared to the $1^{\text {st }}$ and $2^{\text {nd }}$ doses.

\section{Characteristics of Defaulters}

Similar to other studies, genders, methods and place of birth were found not to be a significant factor in this study. ${ }^{9}$ Majority of the children who defaulted immunization was delivered in hospitals $(98 \%)$ and six out of seven were delivered at home (85\%). Only two children (38\%) among the defaulters were unhealthy (fever with temperature more than $38^{\circ} \mathrm{C}$ ) during the immunization schedule, different from the study done in Milwaukee that found $60 \%$ of the children were not immunized up to date as they were unhealthy on the day of scheduled immunization. ${ }^{9}$

Marital status, maternal age and mother's education level were found to be non-significant as compared to other studies. ${ }^{3,10}$ The difference could be caused by different study population or limited sample size. Mother's employment status was found to be significant in this study, and this finding is also different compared to other studies. ${ }^{11,12}$ Twenty-seven percent of employed mothers defaulted compared to only $13.7 \%$ of unemployed mothers.

For the socioeconomic characteristic, bivariate analysis showed family mobility, transportation and cost were found to be significant determinants (Table 3). This finding was similar with other studies. 13,14 However, Yawn reported that cost was not an important barrier for immunization. ${ }^{13}$ Transportation and cost for immunization were the two main outcome expected in this study because the poverty level in Sabah has increased further from $9.8 \%$ in 1999 to $11.6 \%$ in $2004 .{ }^{15}$ On the other hand, waiting time and previous bad experiences at clinics were not the reasons to default immunization in this study, unlike reported by other studies. ${ }^{16,17}$

Multivariate analysis was conducted to find the important determinants while adjusting for other factors. It was found that mother's employment, family size and maternal age were the only significant factors after adjusting for other variables (Table
4). This study found that those factors can explain $65.8 \%$ of the variation in the factors influencing immunization defaulters. Mother's employment was not reported as significant factors before,, 411 but family size was previously reported as a significant reason for suboptimal vaccination. ${ }^{18,19}$ This paper is also in accordance with other studies that showed maternal age as a significant factor for defaulting immunization. ${ }^{11,14}$

The conclusion of this study should have taken into consideration limiting factors such as the adverse immunization experiences inflicted on the babies and mothers. As mentioned in other studies, ${ }^{3}$ emotional distress by permitting the infliction of pain on the babies and their dissatisfaction with the process of immunization contributes to the default behaviour and forgetfulness among mothers, which is the commonest reason for defaulting immunization. ${ }^{8}$ These factors may have an influence on this study outcome.

\section{CONCLUSION}

Reasons influencing defaulting immunization were mother's employment status, family size, and mothers' age. Parents should realise the importance of bringing their children for immunization according to the schedule. To reduce the prevalence of the immunization defaulter, mothers with these profiles need to be given more support and should be monitored closely.

\section{ACKNOWLEDGMENTS}

This study received grant from the Secretariat of Medical Research, UKM Medical Centre (Project Code: FF-173-2006). This study was approved by UKM Medical Centre Research Ethics Committee.

\section{REFERENCES}

1. Clements CJ, Nshimirimanda D, Gasasira A. Using immunization delivery strategies to accelerate progress in Africa towards achieving the Millennium Development Goals. Vaccine 2008;26:1926-33.

2. Brenner RA, Simons-Morton BG, Bhakar $B$,Das A, Clemens JD. Prevalence and Predictors of Immunization Among Inner-City Infants: A Birth Cohort Study. Pediatrics 2001;108:661-70.

3. Falagas ME, Zarkadoulia E. Factors associated with suboptimal compliance to vaccinations in children in developed countries: a systematic review. Curr Med Res Opin 2008;24(6):1719-41.

4. Swennen B, Van Damme P, Vellinga A, Coppieters $Y$, Depoorter AM. Analysis of factors influencing vaccine uptake: perspectives from Belgium. Vaccine 2001; 20:S5-S7.

5. Carr JE, Clements CJ, Martin RM, Ritchie PL- 
J, editors. Behavioural Factors In Immunization. Geneva World Health Organization; 2000.

6. Malaysia MoH. Children Immmunization Facts for Health Workers. In: Ministry of Health Malaysia 2002:10.

7. OI M. Default among mothers attending childhood immunization clinics in llorin, Nigeria. Nigeria Medical Practice 2003; 45:104-7.

8. Onyiriuka A. Vaccination default rates among children attending a static immunization clinic in Benin City. Nigeria Journal of Medi cine and Biomedical Research 2005;4:71-77.

9. Sabnis SS, Pomeranz AJ, Lye PS, Amateau MM. Do missed opportunities stay missed? A 6-month follow-up of missed vaccine opportunities in inner city Milwaukee children. Pediatrics 1998;101:e5.

10. Morrow AL, Rosenthal J, Lakkis HD, et al. A Population-based Study of Access to Immunization among Urban Virginia Children Served by Public, Private, and Military Health Care Systems. Pediatrics 1998; 101:e5.

11. Bundt TS, Hu H-M. National examination of compliance predictors and the immunization status of children: precursor to a developmental model for health systems. Mil Med 2004;169:795-803.

12. Gore P, Madhavan S, Curry D, et al. Predictors of childhood immunization completion in a rural population. Soc Sci Med 1999;48:1011-27.

13. Yawn BP, Xia Z, Edmonson L, Jacobson RM, Jacobsen SJ. Barriers to immunization in a relatively affluent community. J Am Board Fam Pract 2000;13:325-32.

14. Thomas M, Kohli V, King D. Barriers to childhood immunization: findings from a needs assessment study. Home Health Care Serv Q 2004;23:19-39.

15. United Nations Development Programme. Malaysia: Measuring And Monitoring Poverty and Inequality. Malaysia. United Nations Development Programme (UNDP); 2008.

16. Harrington PM, Woodman C, Shannon WF. Low immunisation uptake: Is the process the problem? J Epidemiol Community Health 2000;54:394-400.

17. Bosu WK, Ahelegbe D, Edum-Fotwe E, Kobina $A B$, Kobina Turkson P. Factors influening attendance to immunization sessions for children in a rural district of Ghana. Acta Trop 1997;68:259-67.

18. Haynes $\mathrm{K}$, Stone $\mathrm{C}$. Predictors of incomplete immunisation in Victorian children. Aust N Z J Public Health 2004;28:72-9.

19. Bond L, Nolan T, Lester R. Immunisation uptake, services required and government incentives for users of formal day care. Aust N Z J Public Health 1999;23:368-76. 